\title{
CAMPANHA PELA LIBERDADE DE RAFAEL BRAGA: CORPOS ALIADOS E A PRODUÇÃO DE COMUNIDADES EPISTÊMICAS EM RESPOSTA À ANTINEGRITUDE
}

\author{
RAFAEL BRAGA CAMPAIGN FOR FREEDOM: ALLIED \\ BODIES AND THE PRODUCTION OF EPISTEMIC \\ COMMUNITIES IN RESPONSE TO ANTINEGRITUDE
}

\author{
Rosimeire Barboza da Silva* \\ Viviane de Melo Resende**
}

\section{RESUMO}

Neste artigo nosso objetivo é aprofundar a discussão sobre aspectos discursivos do caso de Rafael Braga, especialmente em torno da Campanha pela Liberdade de Rafael Braga. Tomando a filosofia política de Rancière ao lado dos estudos de multimodalidade de Kress e van Leeuwen e da perspectiva estrutural do racismo no Brasil, olhamos para as falas de membros da Campanha pela Liberdade de Rafael Braga e outros atores em torno do tema e para artefatos multimodais produzidos nesse contexto de mobilização coletiva. Sem pretender realizar uma análise discursiva crítica propriamente, assumimos a tarefa de realizar uma crítica discursiva, que se não toma a linguística a modo de categorias de análise, compreende a relevância do discurso para as cenas de desentendimento que o caso de Rafael Braga e a Campanha pela sua liberdade engendram. Para isso, tomamos parte da etnografia que vimos desenvolvendo ao longo dos últimos seis anos no âmbito do projeto "Entre a justiça e os direitos humanos, o encontro da situação de rua com a lei e com a mídia: o caso Rafael Braga Vieira em diferentes gêneros discursivos" (FAP-DF).

Palavras-chave: campanha pela liberdade de Rafael Braga; discurso; etnografia; cenas de desentendimento; racismo estrutural.

\section{ABSTRACT \\ In this paper our aim is to deepen the discussion on discursive aspects of Rafael Braga's case, especially around the Campaign for Rafael Braga's Freedom. Taking Rancière's political philosophy alongside Kress and van Leeuwen's multimodality studies and the structural perspective of racism in Brazil, we look at the speeches of members of the Campaign for Rafael Braga's Freedom and other actors around the theme, and for multimodal artifacts produced in this context of collective mobilization. Without intending to carry out a critical

\footnotetext{
* Universidade de Coimbra, Centro de Estudos Sociais, Coimbra, Portugal.rosebs@ces.uc.pt Orcid: https://orcid.org/0000-0002-6409-0442

** Universidade de Brasília, UnB, Brasília, DF, Brasil. resende.v.melo@gmail.com

Orcid: https://orcid.org/0000-0002-7791-5757
} 
discourse analysis, we assume the task of conducting a discourse criticism. Linguistics in this paper is not taken as analytical categories, but we understand and emphasize the relevance of language and discourse for the scenes of disagreement that the Rafael Braga's case of the Campaign for his freedom engender. For this, we use part of the ethnography that we have been developing over the past six years.

Keywords: campaign for Rafael Braga's freedom; discourse; ethnography; disagreement scenes; structural racism.

\section{INTRODUÇÃO}

Em dezembro de 2013, o jovem negro e catador de materiais recicláveis, Rafael Braga Vieira foi condenado a cinco anos de reclusão em regime fechado por supostamente ameaçar a ordem pública nas manifestações de rua. $\mathrm{O}$ primeiro condenado pelas Jornadas de Junho, cumpria prisão provisória desde 21 de junho de 2013 e, após a sentença condenatória o seu caso alcançou repercussão devido a série de injustiças que condensa. Uma Campanha pela sua liberdade foi articulada em 2014 e, por meio dela, uma comunidade de litígio se organizou. A exposição do dano que constituiu a prisão de Rafael em 2013 tornou a Campanha uma comunidade epistêmica - união de diversas-os atrizes e atores sociais que produz conhecimentos e sentidos -, que tem pautado, ao longo dos anos, o múltiplo contraditório em torno ao caso.

Nesse sentido, a Campanha produziu representações políticas baseadas numa narrativa que inscreve a trajetória de Rafael Braga, histórica e coletivamente, num contexto mais amplo de espoliação e despojo, no qual o Estado brasileiro se apresenta como incompatível com a presença negra plena. As representações políticas mobilizadas pela Campanha também inauguraram modos de subjetivação política responsáveis por uma série de atos e discursos em relação a temas como seletividade penal, criminalização da pobreza e guerra às drogas que, articulados, expõem o cerne do antagonismo estrutural antinegro da formação social brasileira.

O nosso argumento central é que, em sua habilidade para produzir cenas polêmicas e atualizar formas de expor o dano, reagenciando a palavra e seus contornos na configuração do sensível, a Campanha tem sido responsável sobretudo por suscitar o encontro entre uma lógica policial e uma lógica de reivindicação igualitária, postulando o dissenso como central ao fazer político autônomo e, desfazendo as divisões sensíveis da ordem. Ao denunciar o projeto antinegritude da formação social brasileira, que se expressa de maneira contundente nas instituições do sistema penal, suas-seus protagonistas reivindicam o litígio como aquilo que reúne lógicas heterogêneas de ser em comunidade, rompendo com o consenso das 
respostas fáceis frente ao racismo estrutural. Assim, não é a singularidade do caso Rafael Braga que a Campanha disputa, mas a sua universalidade na lógica antinegra brasileira.

A fim de analisar a articulação da Campanha como uma resposta à antinegritude brasileira, organizamos este artigo em seis seções, além desta introdução e das considerações ao final. Na primeira seção, apresentamos nossa opção metodológica por uma apropriação transdisciplinar das contribuições da multimodalidade, da teoria social e da etnografia para pensar os desafios da investigação crítica em ciências sociais. Na segunda seção, contextualizamos as chamadas Jornadas de Junho como evento que, com a prisão de Rafael Braga, desnuda o antagonismo estrutural antinegro da sociedade brasileira. Na terceira, a contextualização põe em foco a organização da Campanba pela Liberdade de Rafael Braga. A quarta seção retoma a perspectiva filosófico-política de Jacques Rancière para reconhecer os nexos entre desentendimento, dano e palavra/imagem no caso em tela. Na quinta e na sexta seções do artigo, discutimos o dissenso em torno da atribuição do status de preso político a Rafael Braga, buscando mobilizar as perspectivas anteriormente discutidas junto a trechos das entrevistas realizadas e a artefatos multimodais produzidos no esforço político coletivo de denúncia da antinegritude.

\section{MULTIMODALIDADE, TEORIA SOCIAL E ETNOGRAFIA COMO GESTO DE COMPREENSÃO}

O material inédito que constitui a base material deste trabalho inclui algumas das entrevistas realizadas entre maio de 2015 e agosto de 2018 com diferentes atores e atrizes sociais em torno à Campanba pela Liberdade de Rafael Braga. ${ }^{1}$ Além das entrevistas qualitativas, nossas reflexões se beneficiam de um trabalho etnográfico e netnográfico longitudinal, realizado ao longo dos últimos seis anos, que acompanha, compila e analisa diferentes aspectos do caso. Dessa forma, foi possível criar um banco de imagens e materiais gráficos produzidos não só no âmbito da Campanba pela Liberdade de Rafael Braga mas também por iniciativas que têm se ocupado do caso, às vezes de maneira pontual ou esporádica. Esse banco de textos/imagens, mais do que um inventário da gramática visual do caso (KRESS; VAN LEEUWEN, 2006), é um instrumento para compreensão de nexos e sentidos coletivos mobilizados.

1. As entrevistas, realizadas in loco pelas autoras e membras da equipe do projeto, foram transcritas integralmente por meio do software $F_{4}$ audiotranskription, estando sua reprodução autorizada por Termo de Consentimento Livre e Esclarecido, e com aprovação de Comitê de Ética em Pesquisa (CEP-IH/UnB). 
Com presença nas redes sociais e expressiva mobilização virtual, a criação de materiais visuais tem funcionado como elemento central de apelo ${ }^{2}$ à causa e difusão do caso, operando como artefatos multimodais (MARTINEC; SALWAY, 2005). A interação dessas imagens com outras modalidades discursivas nos permite pensar a construção dos significados que se buscou/ busca produzir em torno ao caso Rafael Braga. A discussão que aqui apresentamos está inserida num projeto de pesquisa mais amplo sobre os aspectos discursivos do caso Rafael Braga e os seus encontros com a lei e a mídia. ${ }^{3}$

Como Kress (2011) tem defendido, reunir teorias, disciplinas e metodologias é uma tarefa contingente que responde a necessidades teóricas, descritivas e analíticas específicas. Análises de semiótica social multimodal, teoria social e jurídica, netnografias e etnografias, em nosso caso, são recursos teóricos e metodológicos que vão além de uma triangulação de dados, ao produzir análises multidimensionais que uma teoria só não está apta a produzir (KRESS, 2011, p. 240). Isso é importante assinalar. Apesar de análises discursivas críticas dedicarem atenção às relações entre poder e ideologias que subsidiam a compreensão dos discursos como práticas sociais, a forma como os discursos são comunicados, naturalizados e legitimados, além do nível linguístico, continua a ser um tema pouco desenvolvido desde uma perspectiva crítica (MACHIN, 2013, p. 347). Não são incomuns, assim, análises linguísticas que, ao descuidarem de aspectos sociológicos, jurídicos, econômicos e políticos, incorrem em interpretações desconectadas das condições concretas da realidade social. Aqui não pretendemos realizar uma análise discursiva crítica, mas sim uma crítica discursiva, menos comprometida com o sentido estrito da análise com categorias linguísticas, que com a crítica situada, a interpretação multidimensional conectada aos dados por caminhos transdisciplinares.

Nossa proposta metodológica compartilha, portanto, de uma apropriação sociolinguística de recursos multissemióticos na compreensão da circulação de ideias, valores e identidades, baseada numa descrição aprofundada do contexto social no qual surge e se articula a Campanba pela liberdade de Rafael Braga. E é tal apropriação que torna a descrição útil ao debate das ideologias e concepções

2. 'Apelo’ é um vocábulo mobilizado de forma explícita pela comunidade epistêmica em torno ao caso Rafael Braga, como no título da exposição que reuniu 32 obras de artistas em 2017: Osso - Exposiçãoapelo ao amplo direito de defesa de Rafael Braga, apresentada pelo Instituto Tomie Ohtake, em São Paulo, em parceria com o Instituto de Defesa do Direito de Defesa (IDDD).

3. O projeto de pesquisa "Entre a justiça e os direitos humanos, o encontro da situação de rua com a lei e com a mídia: o caso Rafael Braga Vieira em diferentes gêneros discursivos" é realizado no âmbito do Núcleo de Estudos de Linguagem e Sociedade do Centro de Estudos Avançados Multidisciplinares (NELiS/CEAM) da Universidade de Brasília, com apoio da Fundação de Apoio a Pesquisa do Distrito Federal (FAP-DF). 
incrustadas nas práticas sociais (KRESS, 2011). Descrever a formação da Campanba, suas ações e interações no espaço público é uma das maneiras de nos aproximar, não só do problema político, a injustiça que mobiliza o caso em tela, mas da palavra e da imagem como catalisadoras do dano, veículos de exposição do litígio e condição para o desentendimento que torna o caso Rafael Braga emblemático das bases antinegritude dessa sociedade.

\section{JORNADAS DE JUNHO, FRAGILIDADE DEMOCRÁTICA E PROJETO ANTINEGRITUDE}

Junho de 2013 continua reverberando e interrogando os sentidos que, como sociedade, temos construído e reproduzido ao longo da história brasileira. Naquele momento, diversas de nossas mazelas sociais, políticas e econômicas se viram expostas e foram confrontadas, mas as respostas do Estado naufragaram ao forjar a reiteração de um abismo na bistória. Este abismo, como propôs Teles (2018), é caracterizado pelas contradições entre o desejo democrático e a ausência de memória e justiça.

Embora tenha levado adiante compromissos contraídos com parte do eleitorado ao longo da primeira década dos anos 2000, uma tessitura de consensos e pactos - que buscavam garantir a governabilidade por meio de múltiplas alianças partidárias - conduziu o projeto político progressista do Partido dos Trabalhadores ao que Edson Teles identificou como duas estratégias concomitantes: i) neutralização das reivindicações, em que todas as possibilidades emancipatórias que as lutas e movimentos sociais produziam acabavam por esbarrar nos acordos palacianos; ii) paradigma de governo via estado de exceção, baseado numa emergência que respondia às necessidades do governo e não às necessidades de quem padecia violações (TELES, 2018). A democracia bifronte, por um lado, absorveu e implementou conquistas das lutas sociais, por meio de inéditos arranjos participativos no delineamento de políticas públicas, mas por outro sofisticou as estruturas e as estratégias das instituições autoritárias do Estado.

Ambas as estratégias desse arranjo institucional bifronte se valiam de justificativas articuladas para manter sob controle a dissidência e as críticas internas. Lideranças do Partido dos Trabalhadores (2003-2016) defendiam que essa era a única correlação de forças possível na conjuntura, e que o campo progressista praticaria transformações lentas, mas efetivas, se assumisse uma lógica governamental consensual que legitimasse os acordos em marcha. 
Hoje, sete anos após as primeiras mobilizações, defrontadas com o cenário político atual e o esgotamento do projeto democrático liberal brasileiro, em sua escalada explicitamente autoritária, podemos afirmar que se um abismo no entendimento de nossa história é patente, o entrecruzamento das causas que nos trouxeram até aqui extrapola a razão dual expressa na oposição do projeto democrático versus a ausência de memória e justiça. Com efeito, o que se ensaiou nas ruas nos primeiros estampidos das Jornadas de Junbo - e que logo depois foi apropriado e transformado de maneira radical por grupos antidemocráticos - está ligado irremediavelmente às estruturas autoritárias e antinegritude (VARGAS, 2020) que conformam o substrato mais profundo sobre o qual estão alicerçadas as nossas históricas desigualdades e injustiças.

Não por coincidência, o primeiro condenado pelas Jornadas de Junho foi um homem negro, jovem e catador de materiais recicláveis. Ao descrever o que denomina exclusão antinegra no contexto das manifestações de 2013, Vargas afirma que subjaz a esses eventos a incompatibilidade entre o estado-nação brasileiro e a presença negra plena: a incapacidade que "a formação social brasileira tem de assimilar negras e negros como sujeitos plenos, autônomos e formal e praticamente iguais aos demais sujeitos não-negros" (VARGAS, 2016, p. 13). É, portanto, o antagonismo estrutural antinegro que tem desnudado o impasse de nossa democracia.

Em outras palavras, a democracia liberal que conhecemos, assente em arranjos que sequer atendem às aspirações de direitos individuais e garantias fundamentais de parte da população, e que continua estruturada em oligarquias, não é invenção recente surgida no horizonte das duas décadas anteriores. É conformação social, política e econômica que tem articulado legalidade e exceção, reproduzindo desigualdades e sustentando o projeto nacional desde que este foi instaurado no século XIX.

Se bem podemos elencar algumas reestruturações na matriz produtiva brasileira e certo esforço redistributivo e de reconhecimento, ao longo da primeira década dos anos 2000, a crise mundial de 2008 reforçou os limites desse arranjo. Um tímido projeto reformador que, quando confrontado com as exigências de reorganização do capitalismo financeiro internacional, não foi capaz de sustentar os mesmos níveis de acumulação da riqueza sem acionar as estratégias autoritárias e antinegritude que conformam o seu cerne.

Configurada por relações históricas persistentes, e atualizada cotidianamente em diferentes institucionalidades, analistas poderiam definir a antinegritude como um desarranjo ou fragilidade no seio da democracia nacional. Não o é. A antinegritude e sua conformação a partir das estruturas e instituições que movem 
o projeto brasileiro, resultando no alijamento de grande parte da população da distribuição de riquezas, não podem ser concebidas como desvio, acidente racista ou fragilidade transitória. Antes, devem ser compreendidas como o âmago do projeto em si, que reitera práticas e assegura a reprodução de condições sociais iníquas consolidadas em regras, leis e políticas.

Não há equívoco, ou uma democracia frágil, bifronte, mas um projeto histórico vigoroso e deliberado que busca inviabilizar a existência negra, como o caso Rafael Braga eloquentemente aponta na interrelação de suas diferentes facetas. De maneira contundente, o caso do jovem negro preso numa das maiores manifestações de 2013 expõe os contornos da antinegritude que está na base autoritária do projeto político-econômico brasileiro e o seu modus operandi, o dano sem o qual tal projeto seria irrealizável.

Preso em 20 de junho de 2013, sob a justificativa de portar um coquetel molotov, e assim ameaçar a ordem pública nas manifestações de rua, Rafael Braga Vieira, jovem negro e catador de materiais recicláveis, que vivia entre as ruas do centro e um complexo da zona norte da cidade do Rio de Janeiro, foi o primeiro condenado nas Jornadas de Junbo (RESENDE; SILVA, 2016). Sobre o corpo de Rafael Braga foram exercidas práticas discursivas e materiais que comumente informam as ações do sistema penal brasileiro: o suspeito racializado que sintetiza a perene ameaça negra à cidade branca e que prescinde de provas de delito para ser encarcerado e punido. $\mathrm{O}$ jovem negro, deslocado do cenário de reivindicações, supostamente sem agência política (RESENDE; SILVA, 2018), sobre o qual se exerce impunemente tortura: o semparcela, aquele cuja voz é inaudível por ser concebida apenas como ruído e barulbo, subtraída aos cálculos políticos da aparição pública (BUTLER, 2017; RANCIÉRE, 1996), mas sem a qual, paradoxalmente, é impossível sustentar os níveis de despojo e espoliação que nos caracterizam como nação.

O rito sumário mimetizou disposições e práticas bastante difundidas nos processos de condenação por tráfico de drogas no Brasil (SINHORETTO et al., 2014) em que categoriais raciais, socioeconômicas, etárias, de escolaridade e local de detenção interseccionadas são eloquentes em expressar o delineamento antinegritude do sistema de justiça. Ser jovem, negro, não ter acesso à escolaridade formal, fazer parte de segmentos de baixo poder aquisitivo e viver ou transitar em territórios considerados pelo poder punitivo como livres para o exercício da repressão estatal é ser vulnerável ao recrutamento pelo sistema penal (BRASIL, 2019).

Alguns meses após a prisão e condenação de Rafael Braga em dezembro de 2013, uma Campanha foi articulada para reivindicar a sua liberdade (SOUZA et 
al., 2017). Como veremos nas seções deste artigo, uma multiplicidade de pautas, movimentos e perspectivas políticas coincidem na Campanba pela Liberdade de Rafael Braga. Com algumas vitórias no campo jurídico e um papel central na inscrição do caso na cena pública brasileira, a Campanba foi imprescindível na criação de comunidades epistêmicas em torno às denúncias da seletividade penal, da criminalização da pobreza e da guerra às drogas como estratégias primordiais do projeto antinegritude da sociedade brasileira.

\section{3. "NINGUÉM FICA PRA TRÁS": CAMPANHA PELA LIBERDADE DE RAFAEL BRAGA}

Quando Rafael Braga Vieira se tornou o primeiro condenado no Brasil pelas Jornadas de Junho de 2013, militantes, ativistas, movimentos sociais, coletivos políticos e assembleias populares se deram conta de que, mesmo quando diziam que "ninguém ficaria pra trás", Rafael demorou a ser incluído nas reivindicações coletivas por liberdade e justiça. O 'ninguém' da frase, embora imbuído de um caráter aparentemente universal, sintetizou a falácia que representa a ideia abstrata de igualdade formal em si, e deu relevo ao risco que tais coletivos corriam de serem seletivos ao não enxergar quem não era militante ou vinculado a algum movimento social como parte das lutas por transformação social.

"Já havia um incômodo com um ou outro movimento e organização. Isolados, tínhamos ciência de que havia um caso que não tinha chamado atenção, mas que era tão absurdo quanto qualquer outra ação arbitrária do Estado na repressão àquelas manifestações" (PACHECO, 2014). Segundo Ronilso Pacheco, participante da Campanba, o incômodo inicial em torno do qual se constituiu a Campanba pela Liberdade de Rafael Braga foi uma autopercepção crítica aos limites impostos por uma concepção dominante de agência e sujeito político que, muitas vezes, reproduz uma ideia estática de militância e dos corpos considerados aliados nas demandas por justiça social.

No momento em que a Campanba iniciou a sua trajetória em 2014, a Comissão de Direitos Humanos da Assembleia Legislativa do Rio de Janeiro (ALERJ) já havia se voltado para o caso, bem como o Instituto de Defesa de Direitos Humanos $(\mathrm{DDH})$, que após a Defensoria Pública do Estado do Rio de Janeiro passou a conduzir formalmente a defesa de Rafael Braga em 2014. Mas foi a Rede Fale, ${ }^{4}$

4. De acordo com a descrição da Rede Fale em sua página Facebook, a proposta da organização é produzir informações para campanhas que promovam reflexão e mobilização social com vistas à pressão pública. "No horizonte de atuação do FALE há ações direcionadas especificamente ao público religioso, desenvolvidas nos espaços de igrejas e organizações evangélicas [...] mas há ações que abrangem toda a sociedade, como petições virtuais, manifestações, apoio a iniciativas de movimentos sociais, atividades formativas entre outras". Mais informações: https://bit.ly/2FROpll 
uma rede cristã de defesa de direitos, que "resolveu puxar uma mobilização" (PACHECO, 2014). Procurados, o DDH, o Centro Nacional de Defesa de Direitos Humanos de População em Situação de Rua e Catadores de Materiais Recicláveis (CNDDH-RJ), o Fórum Permanente de População de Rua do Rio de Janeiro e a Agência Papagoiaba uniram-se para produzir uma campanha pela liberdade de Rafael Braga. Nessa fase inicial, foi criada uma página no Facebook intitulada Pela Liberdade de Rafael Braga Vieira, que alcançou boa repercussão e capilaridade, com mais de sete mil curtidas nos primeiros dias de lançamento e que conta atualmente com mais de 50.000 seguidoras-es.

Os primeiros passos também foram impulsionados pela chegada de uma das fundadoras da Assembleia Popular da Grande Tijuca, Sara Celeste Boechat Cordeiro, falecida em 18 de novembro de 2014. Sara Boechat foi uma articuladora imprescindível no início da Campanba, apontada por diversos participantes como uma das responsáveis por imprimir à iniciativa recém-criada três dos elementos fundamentais para a sua consolidação na cena pública como uma comunidade epistêmica: i) a criação de assembleias abertas semanais, realizadas em local público de fácil acesso; ii) a visibilização nacional do caso Rafael Braga e seus sentidos coletivos, e iii) a aproximação entre atores e atrizes sociais, coletivos e individuais, que formavam a Campanba pela Liberdade de Rafael Braga, e a família dele, sobretudo sua mãe, Adriana Braga Vieira, e seus irmãos e irmãs (CAMPOS, 2015; GOMES, 2018; VIEIRA, 2015).

É a partir desse momento que movimentos sociais, ativistas, coletivos de vários pontos da capital carioca, reunidos em campanha pela liberdade do primeiro preso e condenado das Jornadas de Junbo, mobilizam-se em torno a uma cena de desentendimento (RANCIÈRE, 1996). O primeiro desentendimento é suscitado pela prisão de um jovem negro, catador de recicláveis, condenado por supostamente portar um coquetel molotov numa grande manifestação social, mas que alegou desde o princípio não ter participação nos atos. Ao apontar o desentendimento como um dos elementos propulsores da Campanba, retomamos a perspectiva filosófico-política de Rancière (ver próxima seção), da palavra que expõe o dano, o ruído de revolta, a instituição de um litígio na cena dos cálculos políticos da igualdade. Rafael Braga é assim o sem-parte que irrompe na cena polêmica: aquele que "não deveria sequer aparecer nos espaços e agenciamentos da política" (RANCIÈRE et al., 2000, p. 33).

Nos anos subsequentes de construção coletiva, alguns coletivos e movimentos sociais saíram, outros foram incorporados à Campanba. O CNDDHRJ e o Fórum Permanente de População de Rua do Rio de Janeiro se retiraram das articulações, enquanto o Fórum de Juventude do Povo Preto, o Movimento Passe 
Livre do Rio de Janeiro, a Assembleia Popular da Cinelândia, a Assembleia Popular do Méier, a Assembleia Popular do Largo do Marchado, o Fórum de Enfrentamento ao Genocídio do Povo Negro e o Ocupa Alemão foram integrados.

\section{CENAS DE DESENTENDIMENTO: POLÍTICA E POLÍCIA}

Desde o nosso primeiro contato com o caso Rafael Braga em 2013, ficou patente que se tratava de um litígio condensando aspectos múltiplos e relevantes da formação social brasileira. Assim, mais do que um litígio compreendido da perspectiva jurídica, o caso denunciava o desentendimento, ou seja, o processo pelo qual uma cena política é instituída mediante a enunciação de um dano. Nesse processo, conforme Rancière (1996), o logos, como o lugar onde se trava o conflito, institui a política como exigência àquela equação que afasta a palavra, separando o que conta apenas como emissão sonora e o que está apto a emitir juízo. Porque em Rancière política é justamente aquilo que interrompe a ordem da dominação: "Há política - e não simplesmente dominação - porque há uma conta malfeita nas partes do todo" (RANCIÈRE, 1996, p. 25). E há política como desdobramento de um dano ou de um litígio fundamental, na reivindicação de uma parte dos sem-parte de ser ouvida.

É na distribuição simbólica dos corpos - de quem se vê e de quem não se vê - e da palavra que política e polícia podem ser compreendidas como processos antagônicos na configuração do sensível, entendido como o espaço do público. Em Rancière, a polícia é por isso uma ordem que define diferenças entre modos de fazer, ser e dizer; uma designação prévia que delimita e constrange lugares e tarefas. O processo pelo qual uma atividade é compreendida como visível e outra não; uma palavra é compreendida como discurso e outra como ruído (RANCIÈRE, 1996). Mas enquanto a polícia regula o aparecimento dos corpos e as regras do aparecer, do ocupar e das propriedades e distribuição dessas ocupações, a política é o ato que redefine e reconfigura os espaços onde as partes e parcelas, ou ausência delas, se definem. A experiência do dano mobilizada no caso Rafael Braga é política, pois a Campanba, ao deslocar o corpo do jovem negro do lugar que lhe era designado na formação social antinegritude brasileira (GONZALEZ; HASENBALG, 1982; VARGAS, 2016), "faz ver o que não cabia ser visto, faz ouvir um discurso ali onde só tinha lugar o barulho" (RANCIÈRE, 1996, p. 42).

Dessa forma, ao suscitar o encontro entre uma lógica policial e uma lógica de reivindicação igualitária, a política se manifesta como o ato que desfaz as divisões sensíveis da ordem (RANCIÈRE, 1996). E, ao fazê-lo, atualiza uma pressuposição heterogênea: a parte dos sem-parte que manifesta a si mesma. Portanto, ao enunciar o 
desentendimento em torno à prisão, a Campanba pela liberdade de Rafael Braga é responsável por assinalar a política ali onde ela não era nomeada. Apresentando-se como comunidade de litígio e como o múltiplo contraditório frente à ordem policial, a Campanha também inaugura modos de subjetivação política responsáveis por uma série de atos e discursos em relação a temas como seletividade penal, criminalização da pobreza e guerra às drogas que, articulados, expõem o cerne do antagonismo estrutural antinegro da formação social brasileira.

Instaurando a cena política do desentendimento é que a comunidade, política e epistêmica, da Campanba aponta o conflito em torno da existência daquele que, estando ali presente, fora até então subtraído aos cálculos políticos: Rafael Braga. Nessa experiência singular do litígio em torno da palavra e da voz, não é só a Campanba que se constitui, mas também Rafael Braga como o sujeito que expõe o dano, e através do qual a verificação da igualdade assume figura política. Rancière aponta a relevância central do dano na co-constituição de sujeitos políticos e comunidades epistêmicas:

As partes não preexistem ao conflito, que elas nomeiam e no qual são contadas como partes. A 'discussão' do dano não é uma troca - sequer violenta - entre parceiros constituídos. Ela diz respeito à própria situação de palavra e a seus atores. Não há política porque os homens, pelo privilégio da palavra, põem seus interesses em comum. Existe política porque aqueles que não têm direito de ser contados como seres falantes conseguem ser contados, e instituem uma comunidade pelo fato de colocarem em comum o dano que nada mais é que o próprio enfrentamento, a contradição de dois mundos alojados num só: o mundo em que estão e aquele em que não estão, o mundo onde há algo 'entre' eles e aqueles que não os conhecem como seres falantes e contáveis e o mundo onde não há nada. (RANCIẼRE, 1996, p. 40)

Assim, a Campanba como comunidade epistêmica da qual Rafael Braga é parte essencial desfaz e recompõe as relações entre modos de fazer, ser e dizer. O sujeito político coletivo que encarna não é um grupo que "toma consciência de si", " se dá voz" ou "impõe o seu peso", mas um operador que, ao expor o litígio e as condições de desentendimento, "junta e separa as regiões, identidades, funções e capacidades que existem em determinada experiência" (RANCIÈRE, 1996, p. 52). O que a define como comunidade política e epistêmica é sua habilidade para produzir cenas polêmicas e atualizar formas de expor o dano, reagenciando a palavra e seus contornos na configuração do sensível.

\section{TODO PRESO É UM PRESO POLÍTICO}

Uma das primeiras iniciativas amplas da Campanha em 2014 foi reunir, juntamente com o DDH, um conjunto de iniciativas de diferentes instituições, 
coletivos e movimentos sociais dispostos a debater e visibilizar não só a injustiça que essa prisão representava mas as intersecções do caso com a seletividade do sistema penal brasileiro. No bojo dessa primeira articulação nacional, está incrustado o segundo elemento de desentendimento do caso: o dissenso em torno ao estatuto da prisão de Rafael. Com o caso sendo acolhido em distintos espaços, a prisão passou a ser pautada como uma prisão política, uma vez que, como outras prisões do período (DO AMARAL, 2015), ocorreu no contexto das Jornadas de Junbo.

O texto 1, a seguir, é um cartaz digital elaborado pelo Fórum de Oposições pela Base (FOB, hoje Federação das Organizações Sindicalistas Revolucionárias do Brasil) e pela Rede Estudantil Classista e Combativa (RECC), e difundido em redes sociais. $^{5}$

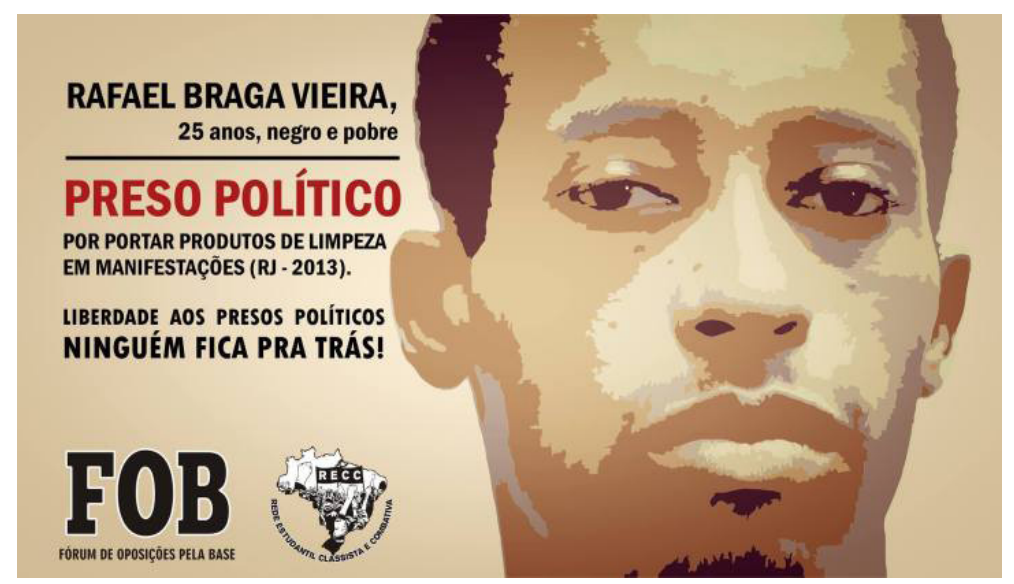

Texto 1. Rafael Braga Vieira - Preso político

O texto, compreendido aqui como artefato multimodal (BOUDON; PARODI, 2014), estabelece relação direta entre o fotograma do rosto de Rafael e a denúncia de preso político "por portar produtos de limpeza em manifestações (RJ - 2013)", reforçando, no sistema tipográfico e nas palavras destacadas em fonte vermelha e maiúscula, tal condição. A dimensão lógico-semântica, que mobiliza ao mesmo tempo uma reivindicação ("liberdade aos presos políticos") e um imperativo da atuação desses grupos: "ninguém fica pra trás", forja no conjunto imagético o rosto de Rafael Braga Vieira como um símbolo. O texto verbal ainda destaca a

5. De acordo com o sítio na internet, ambas organizações surgem como aglutinação de militantes do movimento sindical, estudantil e popular num processo político de oposição ao "governismo" hegemônico no movimento de trabalhadores a partir de 2003. Mais informações https://bit. ly/2Zuq8J4 
idade "25 anos", o pertencimento étnico-racial "negro" e a classe "pobre" de Rafael, que é assim identificado por seus pertencimentos de classe, raça e geração, não só como complemento informacional de seu nome próprio, mas como nexo para a informação destacada em letras capitais vermelhas logo abaixo: "preso político".

Apesar de ser difícil capturar a data de elaboração do texto 1, a menção aos 25 anos de Rafael indica que é uma imagem de 2013. É também de 2013, prévio à formação da Campanba, um dos primeiros pronunciamentos públicos que identifica Rafael Braga como preso político. O texto publicado na página do deputado Chico Alencar (PSOL-RJ) enuncia já no título a condição política da prisão ("Um preso político da democracia brasileira: Rafael Braga Vieira") e compila a intervenção realizada pelo deputado na tribuna da ALERJ na sessão de 17 de dezembro de 2013. ${ }^{6}$ No pronunciamento, o deputado se refere à condição humilhante da prisão de Rafael Braga em junho, "acorrentados seus pés na Delegacia, à moda dos escravos fugidios da servidão no Brasil Imperial". Faz referência a uma entrevista a Rafael Braga realizada por outro deputado do PSOL, Marcelo Freixo, no presídio de Japeri, e relaciona o caso a outro considerado emblemático dos abusos de autoridade e violência policial, o do ajudante de pedreiro Amarildo Dias de Souza (1965-2013), que desapareceu após ser conduzido por policiais militares à Unidade de Polícia Pacificadora da Rocinha em 13 de julho de 2013.

Mais de um ano após a prisão, em novembro de 2014, Pedro Grabois reflete sobre as divergências e convergências entre o caso Rafael Braga e os dos 23 presos políticos de 12 de julho de 2013 (JOURDAN, 2020). Pondera que, se no início a Campanba pela liberdade de Rafael Braga não chegou a empolgar suficientemente a militância dos diversos coletivos cariocas como os atos organizados a favor dos "23", a situação adquiria novos contornos:

Hoje, a luta pela liberdade de Rafael Braga Vieira mostra uma coerência e uma longevidade ainda maior do que a luta pela libertação dos presos políticos de Julho. Acredito que a provocação do pessoal do movimento negro e da luta das favelas teve papel fundamental no aumento da adesão ao caso Rafael. (GRABOIS, 2014, s/p)

Grabois (2014) justifica que contrapor a prisão de Rafael Braga à dos "23" é um exercício fundamental, uma vez que deslinda o nó dos significados mobilizados em torno do reconhecimento como preso político no Brasil, expondo a articulação entre lutas e questão racial. Para Grabois (2014), é importante se perguntar sobre a produção social do crime num país em que o campo progressista investe esforços na compreensão da ditadura, mas ignora sistematicamente a violência da escravidão

6. Para acesso à íntegra do texto: https://bit.ly/3mfzAJQ 
e sua atualização sócio histórica: "Dizer que 'todo preso é preso político' é o caminho para uma crítica sistemática da prisão. [...] o papel ocupado pelo sistema penitenciário no Brasil representa o lugar formidável da articulação das nossas lutas sociais e políticas" (GRABOIS, 2014, s/p).

A perspectiva do autor está baseada no argumento de que em nossa sociedade o racismo é estrutural, ou seja, impõe-se como processo histórico e político, como mecanismo central do poder de Estado (ALMEIDA, 2019). Assim, a prisão de Rafael Braga e a dos "23" seriam incomensuráveis, pois o privilégio representado pela branquitude fixa em posições diferentes manifestantes nãonegros e negros. Contudo, essa incomensurabilidade não deve ser vista como impeditivo para a articulação entre as lutas. Ao contrário, é um convite à reflexão e a uma possível coalizão (BUTLER, 2017) que, ao ser incorporada pela militância não-negra, se traduza no reconhecimento do dissenso: "só colocando os dissensos e as identidades na ordem do dia [...] é possível produzir um polidiálogo capaz de construir alternativas que façam frente aos poderes instituídos e aos sistemas de opressão" (GRABOIS, 2014, s/p).

Em contraponto, entretanto, a cena do desentendimento surge quando Rafael Braga passa a ser compreendido como 'mais um' jovem negro recrutado pela seletividade do sistema penal. Em desacordo com posicionamentos que o identificavam como preso político, novas controvérsias deslocam o debate do contexto das Jornadas de Junbo para o componente corriqueiro da prisão. Em uma das entrevistas, advogadas-os de Rafael abordam tal deslocamento:

\footnotetext{
São dois fatores assim, analisando de forma estrutural. Eu acho que pela nossa estratégia, é um fator. E acho que pelo fato dele ter se tornado mais um do sistema. O que só reforça a nossa tese inicial de que ele nunca foi, ainda que não se entre nessa discussão, ele nunca foi um preso político. Nunca foi. Na verdade, o fato de ele ter sido preso nas manifestações foi o subterfúgio utilizado pelo poder punitivo pra justamente chancelar, de forma ainda mais gravosa, e dar um recado pra os que pretendiam se insurgir, e em razão das condições vulneráveis dele, ele acabou... [...] Acho que essa é uma análise a grosso modo que pode ser feita. (TRISTÃO; LOPES, 2015)
}

Ao longo das entrevistas, as-os advogadas-os reconhecem que, desde a perspectiva da criminologia crítica, que defende o abolicionismo penal, toda prisão é política, pois o sistema penal opera como contingenciador das questões sociais e raciais (DAVIS, 2009; HULSMAN; BERNAT DE CELIS, 1997; WACQUANT, 2000). Contudo, quando não se rechaça a função social que o sistema penal exerce na sociedade, o caso de Rafael seria político em outro sentido:

uma das coisas que fez também com que a gente tomasse a decisão de assumir o caso era justamente de identificar um abandono tanto político quanto... É... Político, principalmente. 
Um abandono do caso, e um abandono justamente porque aquilo ali, na verdade, não é exceção. O Rafael não é o preso político. (TRISTÃO; LOPES, 2015)

Não se tratava de circunscrever Rafael como preso político, mas de politizar o caso para chamar atenção quanto ao descaso que inicialmente lhe foi devotado: "a gente viu a necessidade justamente de politizar a prisão dele. [...] E politizar esse abandono, também. Por que não foi dada atenção a ele? Por que ele é marginalizado pelo Estado e também pelo movimento?" (TRISTÃO; LOPES, 2015). Para as-os advogadas-os, o próprio Rafael discerne entre as imputações jurídicas no contexto da prisão e sua condição:

Ele sabe efetivamente que ele não é um preso político, ele nunca foi. Que ele foi preso porque ele tava realmente em situação de rua. Que ele é mais um pobre, preto, favelado... Ele sabe disso. Essa noção... Essa distinção... ele sabe. [...] Ele sabe efetivamente que ele não é um preso político. Que ele é mais um jovem negro que foi vítima de uma violência estatal. (TRISTÃO; LOPES, 2015)

No mesmo sentido, circunscrevendo a definição de preso político àquele que é encarcerado por opiniões e atos dissidentes, a mãe de Rafael, Adriana Braga Vieira, distingue a prisão do filho das prisões dos " 23 ". Salienta que ele não integrava os protestos, sendo implausível portanto a condenação que lhe estava sendo aplicada:

Preso político é aqueles que tava preso naqueles quebra-quebra. O Rafael não tava. [...] Mas ele não é preso político, não. Ele não tem nada a ver com a política. O Rafael foi preso em outro lugar. [...] Ele falou que ficava numa casa velha, que ele guardava as coisa que ele achava... Sucata que ele achava, então ele guardava tudo lá. [...] Ele falou que quando ele pegou a garrafa que ia saindo na porta, aí disse que dois policial à paisana falou «É neguinho que tá fazendo aí? »... Aí falou que já foi pegando ele, que já foi batendo nele e aí pegou levou ele pra delegacia. (VIEIRA, 2015)

Esse é o mesmo ponto de vista de outro dos atores políticos envolvidos com o caso desde 2013, Wadih Damous, que na ocasião da entrevista era presidente da Ordem dos Advogados do Brasil, seção Rio de Janeiro (OAB-RJ), e da Comissão Estadual da Verdade:

eu acho esse debate meio... porque às vezes acaba chegando à conclusão que todo crime é político, né? Eu acho que se a gente cair nessa conclusão geral de que todo crime é político, isso é um rebaixamento... Porque há pessoas que praticam delitos, motivados pela política... É isso que nós chamamos de crime político. Eu acho que essa definição ainda é a melhor definição. [...] É... quem politizou isso foi o juiz, né? Não é que ele não era um manifestante... O Rafael é um morador de rua, ele não estava se manifestando. Ele estava com a sua atividade habitual de recolher... [...] E ele catou aquilo como cata as coisas, e o juiz resolveu... Como já existe aqui também um processo de pré-condenação [...] Então o Rafael já tava condenado, ao ser pego pelo polícia pra dar o exemplo, né? Existia um contexto de manifestação que aterrorizou determinados setores da classe média aqui e aí você remete à 
formação dos nossos juízes. São juízes normalmente reacionários, são juízes que têm uma formação extremamente positivista, né? São recrutados na classe média com uma ideologia de direita, punitivista, né? (DAMOUS, 2015)

Não é nosso escopo nesse trabalho formular uma posição que referende uma ou outra perspectiva a respeito do estatuto da primeira prisão de Rafael Braga. Antes que eximir-se de um posicionamento nesse sentido, o nosso principal objetivo é chamar a atenção para como o dissenso opera como aglutinador e não impeditivo, dos sentidos construídos e mobilizados por comunidades epistêmicas que lutam por justiça social. O que nos interessa é discutir como, ao ser instaurada a cena de desentendimento em torno à reinvindicação do estatuto político da prisão, a subjetivação política não só de Rafael mas da própria Campanba se dá através de três fatores articulados: a demonstração do dano, que é a denúncia da injustiça mobilizada com a prisão de um inocente; a própria exposição pública do desentendimento entre essas-es atrizes e atores, e a desindentificação operada quando são acionados sentidos divergentes em relação à disputa discursiva de ser, ou não, um preso político. Ou nas palavras de Rancière: o "hiato entre a identidade da ordem vigente e uma nova subjetivação política" que acaba por reconfigurar a comunidade: "Elas dissolvem o consenso que deseja ter grupos bem identificados com interesses específicos, aspirações, valores e 'cultura'" (RANCIÈRE et al., 2000, p. 125).

Assim, é no dissenso e na desindentificação que a política se faz política, expondo o litígio como aquilo que reúne lógicas heterogêneas de ser em comunidade. Não é uma unidade suposta e fictícia em torno a identidades estáveis que engendra o comum, mas o desacordo como princípio e como escolha.

\section{CAMPANHA: A REFIGURAÇÃO DA DIVISÃO DO SENSÍVEL}

A terceira cena de desentendimento é aquela que denuncia o projeto antinegritude da formação social brasileira, que se expressa de maneira contundente nas instituições do sistema penal. Ao pulverizar a exposição do dano sofrido por Rafael Braga em três dimensões concomitantes, a Campanba logrou instaurar inteligibilidade, articulando temas muitas vezes concebidos de maneira fragmentada: seletividade penal, criminalização da pobreza e guerra às drogas.

Os nexos epistêmicos mobilizados visibilizaram conexões entre mecanismos de coerção/consenso e conteúdos epistêmicos, a partir de conjuntos legislativos, regulamentos, dispositivos materiais e fenômenos de autoridade contra o (e a partir do) sistema penal brasileiro. Ao pautar discursivamente três dimensões (texto 2, a seguir) do que identificam como racismo estrutural da sociedade brasileira, e ao 
reconhecer nesses elementos os fatores responsáveis pela prisão e condenação de Rafael Braga, a Campanba produziu representações políticas baseadas numa narrativa que inscreve a trajetória de Rafael Braga, histórica e coletivamente, num contexto mais amplo de espoliação e despojo, no qual o Estado brasileiro se apresenta como incompatível com a presença negra plena (VARGAS, 2016).

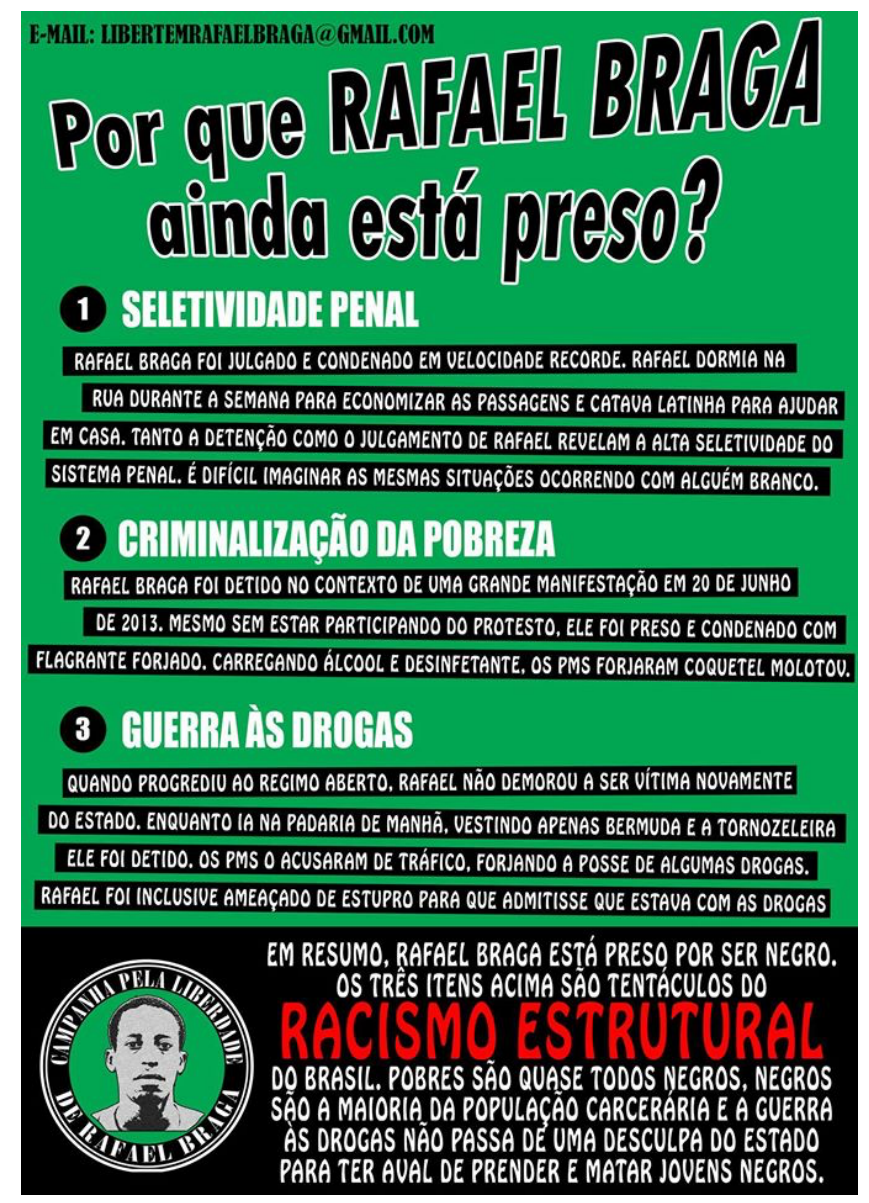

Texto 2: Por que Rafael Braga ainda está preso?

O texto 2 foi elaborado pela Campanha e difundido em redes sociais em 2016. Cumprindo prisão domiciliar e monitorado com tornozeleira eletrônica, Rafael Braga foi novamente preso em janeiro de 2016, quando se deslocava a uma padaria, como testemunhou nos autos do processo. Acusado de associação para fins de tráfico e de tráfico de drogas foi encarcerado preventivamente em regime fechado, julgado 
e condenado em abril de 2017 a 11 anos e três meses de reclusão. A sentença novamente assegurou primazia ao depoimento de policiais militares responsáveis pela prisão, ao amparar-se na súmula 70 do TJRJ, a qual confere poder probatório a tais testemunhos. ${ }^{7}$

Compreendendo o estrato verbal e o estrato imagético, com seus planos ideativo e material, como realização discursiva com interesses de uso presente mas que leva em consideração os usos futuros que possam ter (KRESS; VAN LEEUWEN, 2001), o texto sintetiza, em artefato multimodal, o percurso epistêmico empreendido pela Campanba ao longo de dois anos de mobilização. No texto estão plasmados os principais debates que ocorreram entre 2013 e 2016 tanto nas redes sociais quanto presencialmente nos atos públicos, reuniões abertas, conferências em universidades, debates em comunidades cariocas e em outros municípios brasileiros. A perspectiva cumulativa de um aprendizado coletivo instaurado a partir da exposição do dano que significou a prisão é expressada no trecho final do texto: "em resumo". Em resumo, o que responde à pergunta do cabeçalho "Por que RAFAEL BRAGA ainda está preso?" é o pertencimento étnico-racial de Rafael, "está preso por ser negro". Mas é a articulação entre os "três tentáculos" do racismo estrutural - seletividade penal, criminalização da pobreza e guerra às drogas - que forja a cena do desentendimento, em torno da existência do litígio e das partes que nele se enfrentam. A Campanba sublinha tal perspectiva ao destacar o conceito "racismo estrutural" em fonte vermelha e maiúscula.

Nesse artefato multimodal, a Campanba enuncia o seu enfrentamento com o sistema penal. Se, nas cenas de desentendimento anteriores, o litígio exposto se relacionava diretamente com a situação de injustiça vivenciada por um jovem negro a quem se negava a palavra e se regulava a aparição no espaço do público, agora a cena de desentendimento é substancialmente renovada com o elemento estrutural. Não é a singularidade do caso Rafael Braga que a Campanba disputa, mas a sua universalidade na lógica antinegra brasileira. Ou seja, o caso de Rafael, emblemático por conjugar injustiças variadas, redistribui a maneira como os corpos, de militantes - presos 'políticos' e 'comuns' - e do próprio Rafael se articulam entre as ordens do dizer, do fazer e do ser, refigurando a divisão do sensível por meio da demonstração do direito e da manifestação do justo (RANCIÈRE, 1996). Porque é justo enfrentar a ordem desigual do mundo; é justo denunciar a concertação antinegro do Estado brasileiro no racismo estrutural.

7. Em 2018, num novo desenlace da luta judicial, Rafael Braga foi absolvido do crime de associação para fins de tráfico, embora continue a cumprir pena por tráfico de drogas. 
Ao apontar a centralidade que a questão racial passa a ocupar na Campanha, um dos seus integrantes, Fábio Campos, recorda que o envolvimento do Fórum de Enfrentamento ao Genocídio do Povo Negro do Rio de Janeiro foi fundamental para consolidar uma perspectiva antirracista na mobilização e agendamento público do caso: "Então a gente sempre faz as atividades pautando a seletividade do sistema penal e o genocídio do povo negro [...] a gente sempre leva a questão do Rafael pra esse lado mesmo... Pro lado racial... Que ele tá nessa situação porque ele é negro e pobre" (CAMPOS, 2015). Para Ronilso Pacheco, também membro da Campanba, não é a singularidade do caso que o torna emblemático, mas a contundência com a qual desvela o racismo estrutural de nossa sociedade:

Emblemático sem dúvida. Ele é a ferida exposta de um corte muito mais profundo. O Rafael
não é o único jovem preto, pobre, de trabalho precarizado a estar ocupando uma penitenciária
sem ter sido devidamente ouvido, sem ter cometido o que alegam ter cometido, alvo
deliberado do racismo, da arbitrariedade, do uso indevido e injusto do poder e da seletividade
do estado. Mas ele foi um recorte feito cirurgicamente na nossa desigualdade. Ele estava à
reboque da maior manifestação pública na história da cidade do Rio de Janeiro. A ação da
polícia foi de uma verdadeira caça às bruxas de manifestantes, militantes. Prendeu vários. Só
o Rafael ficou. E por que ficou? As razões mais 'originais' do nosso racismo estrutural: preto,
pobre, semianalfabeto, de trabalho precarizado. Só o Rafael condenado. (PACHECO, 2014)

O projeto antinegritude é o cerne da formação social brasileira, sendo o sistema penal uma das formas concretas de sua expressão. Não é coincidência que, nesse texto 2, a polícia, entendida como uma das instituições que conformam esse sistema, seja acusada pelos-as participantes da Campanba de forjar provas para incriminar Rafael nas duas prisões consecutivas. Tampouco a ênfase na celeridade da condenação nas duas prisões, na "alta seletividade" e na "guerra às drogas" como justificativa, ou como "desculpa do Estado para ter aval de prender e matar jovens negros". Para o jurista Silvio de Almeida, "não seria exagero dizer que o sistema de justiça é um dos mecanismos mais eficientes na criação e reprodução da raça e de seus múltiplos significados" (ALMEIDA, 2019, p. 46). Ou na síntese formulada pela Campanba: "difícil imaginar as mesmas situações ocorrendo com alguém branco".

\section{CONSIDERAÇÕES FINAIS}

Neste artigo, buscamos compreender a relevância do discurso para as cenas de desentendimento que o caso de Rafael Braga e a Campanha pela sua liberdade engendram. Recorrendo a uma apropriação transdisciplinar das contribuições da semiótica social, da etnografia e da teoria social, argumentamos que a habilidade 
para produzir cenas polêmicas e atualizar formas de expor o dano decorrente da prisão de Rafael fez com que a Campanha desencadeasse um encontro entre a lógica policial e a lógica de reivindicação igualitária ao visibilizar injustiças estruturais como resultantes do projeto antinegritude.

Ao contrapor a noção de democracia bifronte à lógica antinegritude da formação social brasileira, buscamos argumentar como, ao invés de uma fragilidade transitória ou acessória, o cerne de nossa democracia liberal está assente na incompatibilidade entre o projeto político econômico e a existência negra plena. Discutimos tal incompatibilidade ao desenvolver uma crítica discursiva às estratégias de mobilização da comunidade epistêmica que se constituiu por meio da Campanha pela liberdade de Rafael Braga.

Ao distinguir polícia e política, com o auxílio da filosofia política de Rancière, compreendemos o dissenso como central à atividade política em contraponto aos consensos superficiais formados em torno aos efeitos do racismo estrutural. Essa distinção, analisada em três cenas de desentendimento suscitadas pelas intervenções da Campanha na cena pública, permitiu-nos compreender como a palavra veiculada como exposição do dano torna-se prática social ao refigurar a divisão do sensível. Defendendo Rafael como o sem-parte apto a emitir juízo, a Campanha interfere nos cálculos pré-determinados da política, denunciando o caráter antinegritude das assimetrias presentes no interior das relações democráticas.

A articulação entre material etnográfico, entrevistas e textos multimodais nos proporcionou compreender os nexos e os sentidos que vão do apelo pela liberdade de Rafael à denúncia do cerne antinegritude do projeto brasileiro. Assumir o logos como o lugar onde se trava o conflito permite à Campanha instituir a política como exigência e empreender a reconfiguração dos espaços onde as parcelas se definem. É por meio dessa redefinição que a denúncia do projeto antinegritude se consolida em sua trajetória epistêmica. O conhecimento cumulativo originado em debates e mobilizações presenciais e virtuais desemboca no vislumbre dos 'tentáculos' do racismo estrutural: seletividade penal, criminalização da pobreza e guerra às drogas. E também na defesa intransigente de uma sociedade antirracista.

Diferente de outras campanhas célebres pela libertação de presos-as sobretudo considerados-as políticos-as -, a projeção do caso de Rafael Braga levou a algumas encruzilhadas táticas, seja no nível técnico da defesa jurídica, seja no campo da execução da pena. A publicidade inédita e, de algum modo, impensável para os padrões do sistema penal fluminense reverberou em situações específicas de recrudescimento da vigilância e tortura contra o seu corpo negro, agora retirado do anonimato e projetado, simbólica e materialmente, em diversos pontos da cidade. 
Com seu rosto estampando os mais diversos suportes, desde murais a grafites, passando por bottons e lambe-lambes, Rafael Braga passou a sintetizar, veicular e denunciar, em sua imagem e seu corpo negro, o abismo das desigualdades brasileiras, forjadas no racismo estrutural e estruturante, e na seletividade do sistema penal.

Um ponto de tensão para o qual nossa atenção está voltada atualmente é a tessitura ética e relacional de construção desses espaços, onde nós e conflitos apontam a relevância de defender, científica e eticamente, a integridade de Rafael Braga, como pessoa sistematicamente violentada pelo racismo estrutural que tantas vezes denunciamos. Nesse sentido, a defesa dessa integridade passa pelo compromisso de não confundir a singularidade, individualidade e subjetividade de Rafael Braga com os condicionantes sociais e históricos que sua vida condensa. Trata-se de condição que transcende, porque situada e interconectada com outras tantas e muitas vidas negras. Importam.

\section{REFERÊNCIAS}

ALMEIDA, Silvio Luiz de. Racismo estrutural. Selo Sueli Carneiro. São Paulo: Pólen, 2019.

BOUDON, Enrique; PARODI, Giovanni. Artefactos multisemióticos y discurso académico de la Economía: Construcción de conocimientos en el género Manual. Revista signos, v. 47, n. 85, p. $164-195,2014$

BRASIL, Ministério da Justiça e Segurança Pública. Levantamento Nacional de Informações Penitenciárias (Atualização - Junbo de 2017). Brasília: Departamento Penitenciário Nacional, 2019. Disponível em: http://depen.gov.br/DEPEN/depen/sisdepen/ infopen/relatorios-sinteticos/infopen-jun-2017-rev-12072019-0721.pdf.

BUTLER, Judith. Cuerpos aliados y lucha politica: hacia una teoría performativa de la assamblea. Barcelona: Paidós, 2017.

CAMPOS, Fábio. Caso Rafael Braga Vieira (Entrevista pessoal): Campanba pela Liberdade de Rafael Braga. Rio de Janeiro, 2015.

DAMOUS, Wadih. Caso Rafael Braga Vieira (Entrevista pessoal): OAB-RJ e Comissão Estadual da Verdade/RJ. Rio de Janeiro, 2015.

DAVIS, Angela Y. A democracia da abolição: para além do império das prisões e da tortura. Rio de Janeiro: Difel, 2009. 
DO AMARAL, Augusto Jobim. Polícia e democracia: O tempo que resta das jornadas de junho de 2013. Sistema Penal \& Violência (Online), v. 6, n. 2, p. 174-195, 2015

GOMES, Ailton. Caso Rafael Braga Vieira (Entrevista pessoal): Campanba pela Liberdade de Rafael Braga. Rio de Janeiro, 2018.

GONZALEZ, Lélia; HASENBALG, Carlos Alfredo. Lugar de negro. Rio de Janeiro: Editora Marco Zero, 1982. v. 3.

GRABOIS, Pedro. A vida no asfalto não é mais o centro de gravidade da cidade. Universidade Nômade Brasil, Rio de Janeiro, 20 nov. 2014 Disponível em: https://bit.ly/2DSpcGC. Acesso em: 12 set. 2020.

HULSMAN, Louk; BERNAT DE CELIS, Jacqueline. Penas perdidas: o sistema penal em questão. Niterói: Luam, 1997.

JOURDAN, Camila. 2013: Memórias e resistências. São Paulo: Hedra, 2020.

KRESS, Gunther R. 'Partnerships in research': multimodality and ethnography. Qualitative Research, v. 11, n. 3, p. 239-260, 2011.

KRESS, Gunther R.; VAN LEEUWEN, Theo. Multimodal discourse: the modes and media of contemporary communication. London: Hodder Arnold, 2001.

KRESS, Gunther R.; VAN LEEUWEN, Theo. Reading images: The grammar of visual design. 2nd ed. London: Routledge, 2006.

MACHIN, David. What is multimodal critical discourse studies? Critical discourse studies, v. 10, n. 4, p. 347-355, 2013.

MARTINEC, Radan; SALWAY, Andrew. A system for image-text relations in new (and old) media. Visual communication, v. 4, n. 3, p. 337-371, 2005.

PACHECO, Ronilso. Caso Rafael Braga Vieira (Entrevista pessoal): Campanba pela Liberdade de Rafael Braga. Rio de Janeiro, 2014.

RANCIÈRE, Jacques. O Desentendimento: Política e Filosofia. Tradução Ângela Leite Lopes. São Paulo: Edições 34, 1996.

RANCIÈRE, Jacques. Literature, politics, aesthetics: Approaches to democratic disagreement. Interviewed by S. Guenoun \& J. Kavanagh. SubStance, v. 92, p. 3-24, 2000 . 
RANCIÈRE, Jacques; PANAGIA, Davide; BOWLBY, Rachel. Ten Theses on Politics. Theory \& Event, v. 5, n. 3, 2001. Disponível em: https://doi.org/10.1353/tae.2001.0028. Acesso em: 10 set. 2020.

RESENDE, Viviane de Melo; SILVA, Rosimeire Barboza da. Jornadas de junho e criminalização da situação de rua no Brasil: o caso Rafael Braga Vieira. In: PARDO ABRIL, Neyla Graciela (org.). La sociedad, la comunicación y sus discursos. Miradas Interdisciplinares. Bogotá: Universidad Nacional de Colombia: Instituto Caro y Cuervo, 2016. p. $125-162$.

RESENDE, Viviane de Melo; SILVA, Rosimeire Barboza da. O encontro da situação de rua com a lei e com a mídia: o caso Rafael Braga Vieira em o Globo.Com. In: MONTECINO, Lésmer (org.). Memorias de la Calle. Santiago de Chile: Editorial Cuarto Proprio, 2018. p. 275-338.

SINHORETTO, Jacqueline; SILVESTRE, Giane; SCHLITTLER, Maria Carolina. Desigualdade racial e segurança pública em São Paulo: letalidade policial e prisões em flagrante (Sumário executivo). São Carlos: Universidade Federal de São Carlos, 2014.

TELES, Edson. O abismo na bistória: ensaios sobre o Brasil em tempos de Comissão da Verdade. São Paulo: Alameda, 2018.

TRISTÃO, Henrique; LOPES, Raphaela. Caso Rafael Braga Vieira (Entrevista pessoal): Instituto de Defensores de Direitos Humanos (DDH). Rio de Janeiro, 2015.

VARGAS, João H. Costa. Desindentificação: a lógica da exclusão antinegra no Brasil. In: PINHO, Osmundo; VARGAS, João H. Costa (org.). Antinegritude: o impossível sujeito negro na formação social brasileira. Belo Horizonte: EDUFRB, 2016. p. 13-30.

VARGAS, João H. Costa. Racismo não dá conta: antinegritude, a dinâmica ontológica e social definidora da modernidade. Revista Em Pauta: teoria social e realidade contemporânea, v. 18, n. 45,2020 , p. $16-26$.

VIEIRA, Adriana Braga. Caso Rafael Braga Vieira (Entrevista pessoal): Família. Rio de Janeiro, 2015.

WACQUANT, Loïc. The New "Peculiar Institution": On the Prison as Surrogate Ghetto. Theoretical Criminology, v. 4, n. 3, p. 377-389, 2000. Disponível em: https://doi.org/ 10.1177/1362480600004003007. Acesso em: 27 set. 2014.

Recebido: 13/9/2020

Aceito: 11/10/2020

Publicado: 14/10/2020 